\title{
ACUTE RESPIRATORY ILLNESS IN VOLUNTEERS FOLLOWING INTRAMUSCULAR ADMINISTRATION OF LIVE ADENOVIRUS
}

\author{
By M. R. HILlEMAN, R. E. HODGES,1 M. S. WARFIELD, ANd S. A. ANDERSON \\ (From the Department of Respiratory Diseases and the Special Operations Branch, Walter \\ Reed Army Institute of Research, Washington, D. C.)
}

(Submitted for publication February 6, 1957; accepted March 8, 1957)

\begin{abstract}
Early investigations of the pathogenicity of the adenoviruses (RI-APC-ARD agents) (1-5) for
\end{abstract} man revealed $(3,6,7)$ that volunteers given tissue culture-grown virus by respiratory, intradermal, or intramuscular routes regularly developed neutralizing and complement-fixing antibodies against the agents without significant illness. This finding led us to attempt to prepare live virus vaccine for human immunization employing types 4 and 7 adenovirus grown in tissue cultures of monkey kidney. When it was found $(8,9)$, however, that monkey kidney cultures may contain "wild" viruses of ùnknown pathogenicity for man, the idea of using such untreated monkey kidney material in volunteers was abandoned and a formalin-killed vaccine was prepared instead. The high degree of effectiveness of the killed vaccine in preventing acute respiratory illnesses caused by adenovirus in newly inducted soldiers has been reported elsewhere (10-12).

Continued investigation of the live virus vaccine problem was made, employing types 3,4 , and 7 adenovirus produced in tissue cultures of human embryo intestine which had been propagated serially in vitro. Contrary to expectation, volunteers given the trivalent live virus preparation intramuscularly developed acute febrile respiratory illness which resembled closely the natural disease caused by these agents. This report describes the experimental illness induced in the volunteers and presents the antibody responses in these individuals.

\section{MATERIALS AND METHODS}

\section{Preparation of virus for human injection}

Tissue cultures of human intestinal cells. The virus injected into the volunteers was propagated in human embryonic intestinal cells of non-malignant origin. This cell line was initiated by Dr. Gertrude Henle and her associates (13) from a plasma clot explant culture of hu-

\footnotetext{
1 Present address : Department of Medicine, School of Medicine, University of Iowa, Iowa City, Iowa.
}

man embryonic small intestine grown in nutrient medium containing human serum. The cells originally propagated in tissue culture grew slowly and resembled fibroblasts and histiocytes. In the fourth passage, epithelial-like cells appeared which rapidly overgrew the culture and were predominant thereafter. The origin of the epithelial-like cells is unknown but these may have been present from the start, having been obscured by the more numerous fibroblasts, or they may have been derived by "transformation" from some previously existing cell type.

After 20 passages in Dr. Henle's laboratory, the culture was sent to Microbiological Associates, ${ }^{2}$ Bethesda, Maryland, where it was passed in a medium consisting of Eagle's basal medium with 10 per cent horse serum. In each passage the culture fluid was removed, the cell layer digested with trypsin solution and the cells planted in fresh horse serum nutrient. Tissue cultures employed to grow the adenoviruses had been passed 16 to 23 times in the horse serum nutrient. For virus propagation, these cultures were washed five times with synthetic mixture 199 to remove the serum nutrient and were maintained in this solution with 100 units of penicillin and $100 \mu \mathrm{g}$. streptomycin per $\mathrm{ml}$.

Virus. The adenovirus type 3 strain RI-55-33 and type 4 strain RI-55-32 were recovered in cultures of human intestine from the throat washings of military patients with undifferentiated acute respiratory disease (ARD) (14). Type 7 strain RI-4-202 was recovered in human amniotic epithelium culture from throat washings of a patient with ARD and, after one additional passage in such cells, was propagated in cultures of human intestine. These viruses grew abundantly in human intestine cultures causing total degeneration in 24 to 48 hours resembling that described (1) for the $\mathrm{HeLa}$ strain of human epidermoid carcinoma cells.

To prepare virus for human injection, 32-oz. prescription bottle cultures of human intestine, maintained with $25 \mathrm{ml}$. of mixture 199 containing antibiotics, were inoculated each with $1 \mathrm{ml}$. of undiluted seed virus. After 2 days' incubation at $36^{\circ} \mathrm{C}$., the whole cultures were homogenized for 3 minutes in a Waring blendor and the supernatant fluid obtained following low speed centrifugation was further clarified by filtering through a sintered glass filter of medium porosity. A sample of each filtrate was saved for individual testing. A pool comprising equal volumes of the types 3,4 , and 7 viruses was prepared

2 All tissue cultures and tissue culture media employed in this investigation were obtained from Microbiological Associates, Bethesda, Maryland. 
for human use and stored frozen at $-70^{\circ} \mathrm{C}$. in sealed glass ampoules until injected into volunteers 2 months later.

Safety, identity, and sterility tests. Tests for safety and sterility of the trivalent virus pool were carried out in suckling and adult mice, guinea pigs, rabbits, monkeys, and a variety of artificial media as described previously $(10,11)$ for the formalin-killed bivalent adenovirus vaccine. Additionally, 2 serial passages of the virus in 6and 10-day chicken embryos by the yolk sac and allantoic routes were carried out; the embryos remained normal and no hemagglutinins for human " $O$ " or chicken red blood cells were present in the allantoic fluids. Neutralization tests using monotypic rabbit antisera were carried out in HeLa and monkey kidney cell tissue cultures as described earlier (1); these served to identify the virus in the monovalent filtrates and showed the absence of other detectable cytopathogenic agents.

\section{Virus laboratory tests}

Virus recovery attempts from patients' throat washings or eye swabs were carried out in duplicate in $\mathrm{HeLa}$ and human intestine tissue cultures by the same general methods described earlier $(1,10)$. Passage of the triturated whole cultures was made at 5- to 7-day intervals and from 3 to 7 such serial passages of each isolation attempt were made. Each eye specimen was tested one time in $\mathrm{HeLa}$ and human intestine cell cultures and each throat washing from 2 to 5 times in $\mathrm{HeLa}$ and 2 or 3 times in human intestine cells.

Serology. The methods for the complement-fixation (C.F.) and neutralization tests were described previously (1). Type 4 strain RI-67 virus grown in HeLa cell tissue culture was employed for C.F. antigen and types 3 , 4, and 7 strains RI-3-110, RI-67, and RI-4-202 (2), respectively, propagated in $\mathrm{HeLa}$ cultures were used to measure neutralizing antibody. All serum titers are expressed as the greatest initial dilution of serum which caused complete or nearly complete fixation of complement or of suppression of virus growth (neutralization).

Human volunteers. The human volunteer study described here was intended primarily to be an additional test of safety to detect hepatitis virus which might have been carried-though only a remote possibility-in the human intestine cell line used to propagate the adenoviruses. Five of the six volunteers were adult male civilian employees of the Walter Reed Army Institute of Research and the other was a commissioned officer assigned to the Institute. All the volunteers were fully aware of the possible dangers involved. No epidemic of acute respiratory illness occurred in the personnel of Walter Reed Army Institute of Research either immediately preceding the time of the injection of virus or during the following 3-week period. Additionally, tests of the preinoculation and 2-week post-injection sera from each volunteer showed no diagnostic increase in hemagglutinationinhibiting antibody against type A prime (FLW-1-52) or type $B$ (Lee and IB1) influenza viruses.

Prior to injection, each volunteer was given a chest $\mathrm{X}$-ray and a detailed hospital admission type of physical
TABLE I

Composition of trivalent adenovirus preparation

\begin{tabular}{|c|c|c|c|c|c|}
\hline \multicolumn{2}{|r|}{ Virus } & \multicolumn{2}{|c|}{$\begin{array}{l}\text { Human tissue culture } \\
\text { passage }\end{array}$} & \multicolumn{2}{|c|}{ Titers } \\
\hline Type & Strain & Amnion & $\begin{array}{l}\text { Intes- } \\
\text { tine }\end{array}$ & $\begin{array}{l}\text { Infec- } \\
\text { tivity }\end{array}$ & C.F. \\
\hline $\begin{array}{l}3 \\
4 \\
7\end{array}$ & $\begin{array}{l}\text { RI-55-33 } \\
\text { RI-55-32 } \\
\text { RI-4-202 }\end{array}$ & $\begin{array}{l}0 \\
0 \\
2\end{array}$ & $\begin{array}{l}9 \\
8 \\
7\end{array}$ & $\begin{array}{l}10^{-2} \\
10^{-2} \\
10^{-2}\end{array}$ & $\begin{array}{l}1: 16 \\
1: 4 \\
1: 8\end{array}$ \\
\hline
\end{tabular}

examination with special attention to inspection of the eyes, ears, nose and throat. All volunteers were in good health at the time of inoculation. Daily clinical observations of the volunteers were made during the first 9 days and periodically thereafter for 6 to 8 months. Samples of blood, for serological testing, and throat washings and conjunctival swabs, for virus recovery attempts, were taken at the time periods indicated in the clinical charts. The specimens were stored frozen in sealed containers at $-20^{\circ} \mathrm{C}$. or at $-70^{\circ} \mathrm{C}$. until examined.

\section{RESULTS}

\section{Trivalent live virus pool}

The composition of the types 3,4 , and 7 adenovirus pool injected into the volunteers is shown in Table I. The infectivity titer of each strain was $10^{-3}$ and the C.F. titers ranged from $1: 4$ to $1: 16$. The total nitrogen value for the pool was 0.213 $\mathrm{mg}$. per $\mathrm{ml}$. and the protein nitrogen content was $0.024 \mathrm{mg}$. per $\mathrm{ml}$.

The six volunteers in the study were each given $1 \mathrm{ml}$. of the trivalent live virus preparation at approximately 4:00 P.M. on day 0. Unexpectedly, in view of previous experience $(3,6,7)$, five of the six volunteers developed an acute upper respiratory illness which resembled that described for $\operatorname{ARD}(14,15)$ with conjunctivitis (16) and for pharyngoconjunctival fever (17). Basically the same illness occurred in each case but the degree of severity differed markedly. Three patients (cases 1, 2, and 3) had a moderately severe illness while two (cases 4 and 5) developed a mild form of disease. Case 6 also developed respiratory symptoms but these were so mild that they might not have been recognized had they not been searched for. Three of the patients, two with severe and one with mild illness, experienced a moderately severe primary toxic reaction shortly following injection of virus. The clinical picture and the laboratory findings in each of the patients are described in the summaries which follow. 


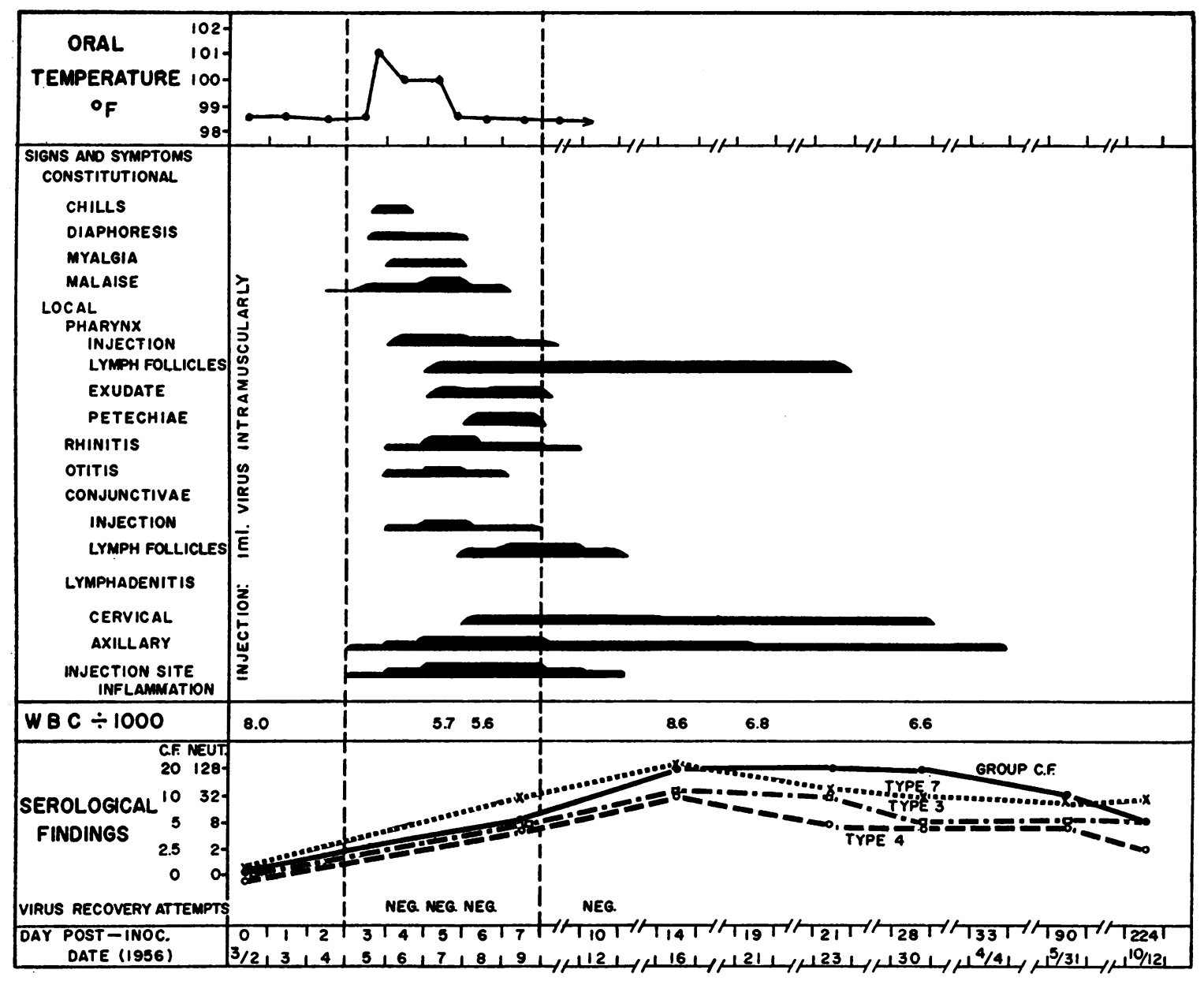

Fig. 1. Case 1, Clinical and Laboratory Findings

\section{Case summaries}

Patient 1, Figure 1. On the third day after inoculation, this 39-year-old man, who was previously well, complained of feeling listless and of soreness of the injection site. Late the same evening there was an abrupt onset of constitutional symptoms which consisted of generalized aching of the back, arms, and legs followed shortly by chills, sweating, and a temperature rise to $101^{\circ} \mathrm{F}$.

The patient continued to feel ill on the following day at which time the localized signs and symptoms began. The patient complained of generalized aching, pain in the left ear, coryza and a sore throat. On physical examination, the conjunctivae were found to be injected and the left tympanum was erythematous and retracted. The nasal mucosa was inflamed and edematous and there was a watery discharge. The pharynx was also edematous and acutely inflamed. The site of injection was swollen, erythematous, indurated, and painful and the corresponding axillary nodes were markedly enlarged and very tender. The acute illness continued through the fifth day when the patient complained of generalized aching, fatigue, and excessive sweating. The inflammation of the conjunctivae, ears, and nasal mucosa had increased. Hyperplastic lymph follicles appeared on the posterior wall of the intensely inflamed pharynx and an easily removable whitish exudate of "pin-head" size surmounted the surface of many of these follicles. A few enlarged sublingual nodes were also present. The site of injection was elevated, intensely inflamed and swollen, involving an area of erythema of $8 \mathrm{~cm}$. diameter and the corresponding axillary nodes were now 2 to $3 \mathrm{~cm}$. in size.

Recovery from the acute illness began on day 6 when the temperature returned to normal. The conjunctivitis, however, had not diminished and the right eye at this time revealed intense injection and suffusion of the bulbar and palpebral conjunctivae. Lymphatic hyperplasia produced elevations of the mucosal surface. Inflammation of the ear, nose, and throat had subsided but petechiae were noted about the base of the uvula. The pharyngeal follicles were increased in size and exudate was present on most of these elevations. Sublingual nodes were prominent. The injection site revealed increased 
inflammation, induration, and tenderness but was not fluctuant. The axillary nodes were enlarged bilaterally but those corresponding to the injection site were larger and more tender. Recovery was uneventful and was characterized by rapid diminution of the inflammation with a more gradual reduction of the lymphatic hypertrophy. No further illness or significant physical changes occurred in the patient during the remaining 7 months of observation.

Chest $\mathrm{X}$-rays made prior to and 7 days post-inoculation were negative. The total and differential white blood cell counts remained within normal limits throughout the observation period. Serum bilirubin levels, performed to detect hepatic dysfunction, were within normal limits throughout the study period. Cultures of the throat made on the fourth and sixth days during the acute illness revealed a normal bacterial flora. Adenovirus could not be recovered from the eye on day 6 or from the throat on days $4,5,6$, or 10 . There was no detectable neutralizing antibody against types 3,4 , or 7 virus in the pre-inoculation serum specimen but antibody to all 3 types was already present on day 7 when the illness was in the acute inflammatory stage. Maximal titer levels were reached by the fourteenth day.

Patient 2, Figure 2. Seven hours following injection of virus, this 39-year-old man who was previously well experienced an abrupt onset of constitutional symptoms characterized by shaking chills with fever up to $103^{\circ} \mathrm{F}$., sweating, and generalized aching of the back and extremities. This was accompanied by nausea and one episode of vomiting. There were no localizing signs and the intermittent fever and constitutional symptoms subsided by the third day. On day 4 the temperature rose again to $101.2^{\circ} \mathrm{F}$. and ushered in the acute respiratory illness. The patient complained of a sore throat, nasal discharge, and mild anorexia. The conjunctivae of both

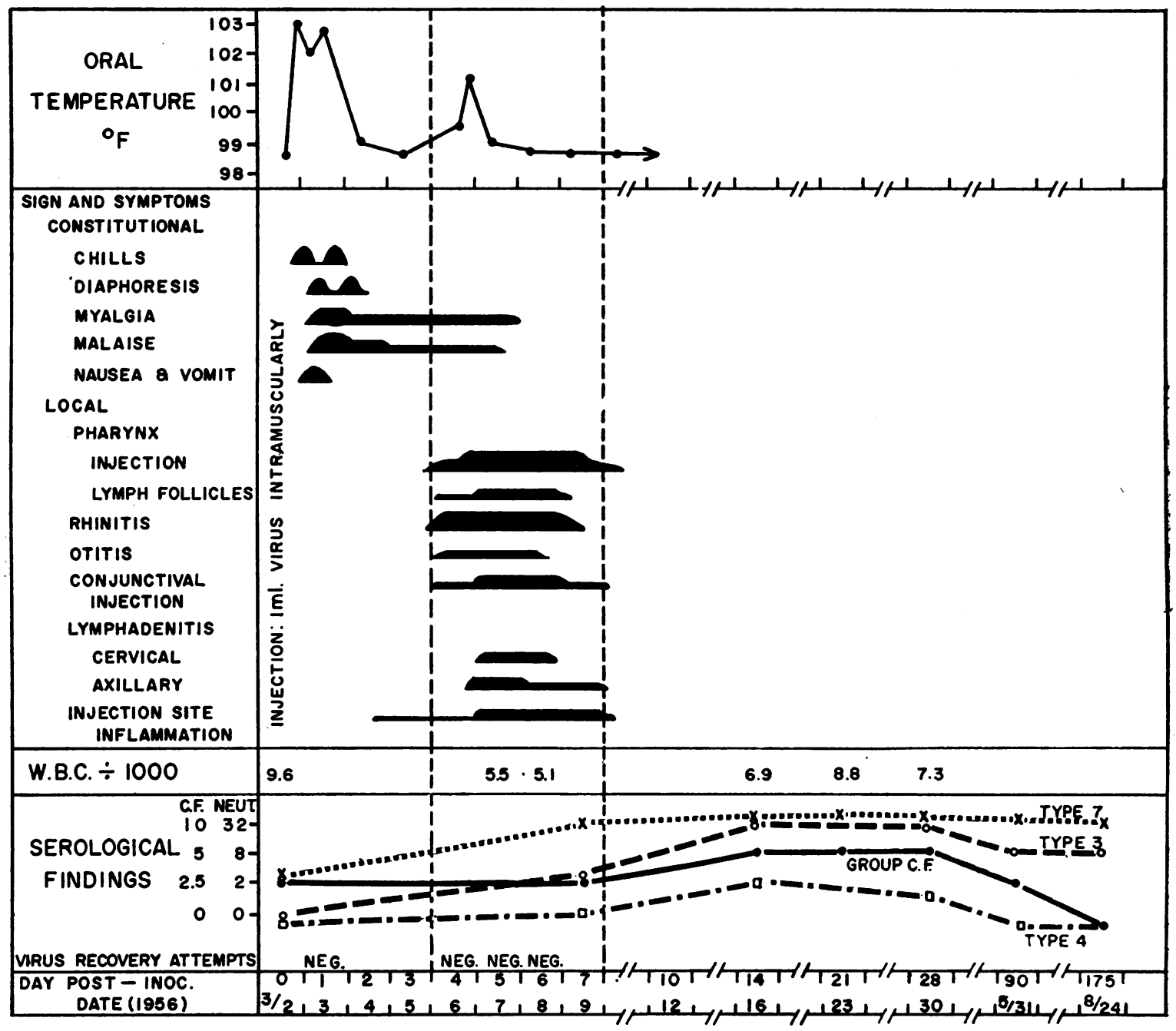

Fig. 2. CASE 2 


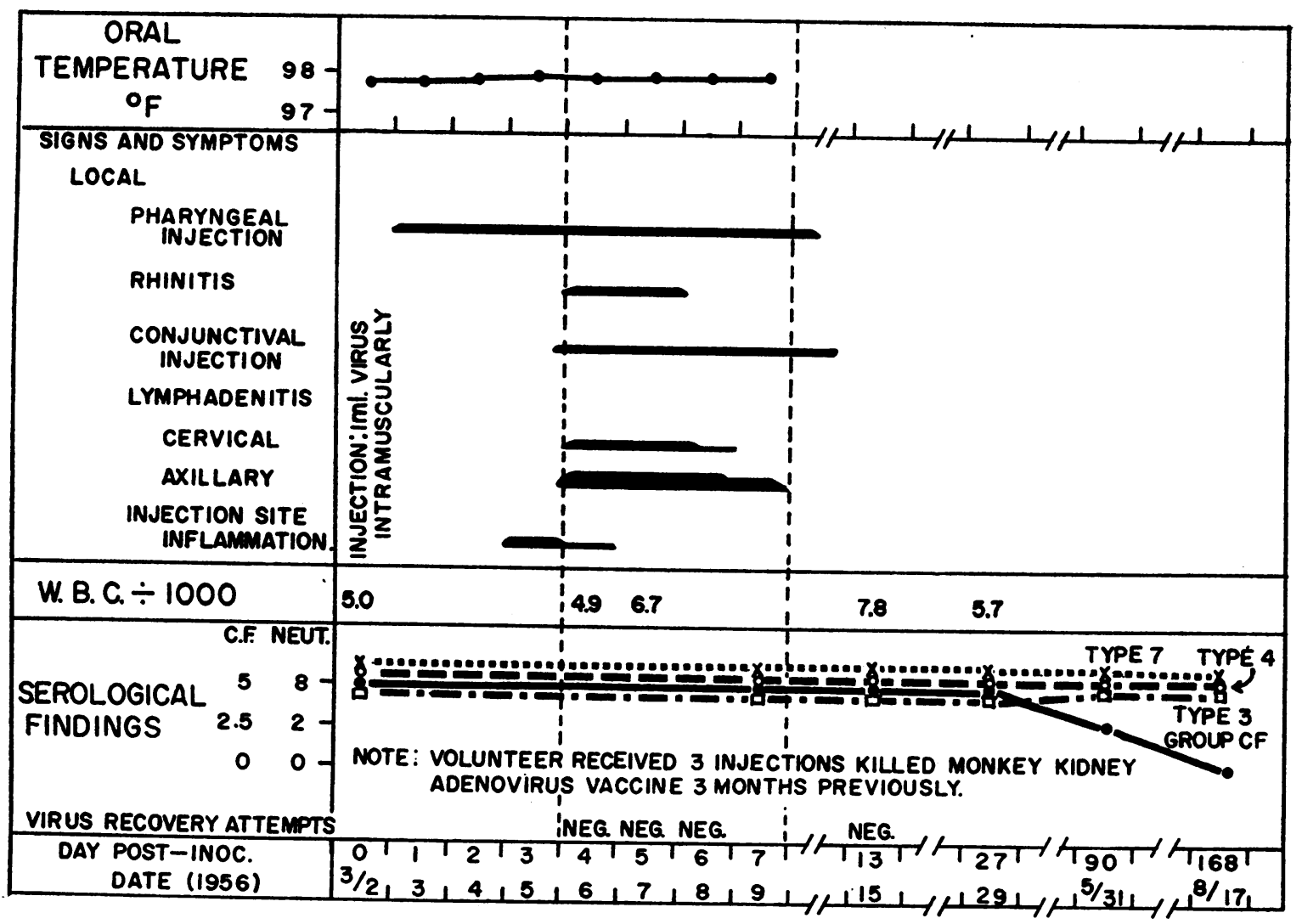

Fig. 3. CASE 6

eyes were moderately injected but were not granular. Otitis consisting of marginal inflammation of the tympani was present. The nasal mucosa was acutely inflamed and edematous. A clear, watery nasal discharge was noted which lasted for 2 days and then became mucopurulent. The pharynx was injected and lymphatic follicles were present. This inflammation of the mucous tissues disappeared by the end of the seventh day. Lymph node enlargement was only moderate and involved the nodes of the posterior cervical region and the axilla of the side on which the injection was made. This lymphatic hypertrophy regressed by the seventh day and did not recur. The local reaction at the injection site, which began on day 2 as erythema and tenderness, became more intense by day 5 when it was $7 \mathrm{~cm}$. in diameter, but returned to normal by the seventh day. No further significant changes occurred in the patient during the 6 months which followed.

The total and differential white blood counts and the sedimentation rate were normal throughout the observation period. Serum bilirubin levels remained within normal limits. Chest $\mathrm{X}$-rays made prior to and on day 7 post-inoculation were negative. Cultures of the throat made on the fourth and sixth days showed a normal bacterial flora. Adenovirus could not be recovered from the throat washings of the patient collected on days 1,4 ,
5, or 6. Neutralizing antibody to type 7 virus only was present in the pre-inoculation specimen. There was antibody increase to all 3 types and the maximum titer was reached by the fourteenth day.

Patient 3. This 31-year-old volunteer developed a primary toxic reaction with fever to $102.6^{\circ} \mathrm{F}$. similar to that described for patient 2 . A moderately severe respiratory illness developed on the third day post-inoculation characterized by fever to $100^{\circ} \mathrm{F}$., malaise, bilateral granular conjunctivitis, otitis, rhinitis, pharyngitis with oral lymphatic hypertrophy but without exudate, tonsillitis, nonproductive cough and cervical and axillary (injection side) lymphadenopathy. Two small cystic structures which persisted for 2 weeks were present in the palpebral conjunctivae. The acute inflammatory stage of the illness subsided by the seventh day post-injection but the lymphadenopathy persisted for 2 weeks longer. There was no further clinical change during the 172-day observation period. The chest $\mathrm{X}$-rays remained negative throughout and there was no significant change in the white blood cell count, sedimentation rate or level of serum bilirubin. Throat cultures revealed a normal flora and attempts to recover adenovirus from the eyes and throat on days 4,5 , and 6 post-inoculation were negative. The patient had neutralizing antibody against type 7 virus only in his preinoculation specimen. Marked antibody increase against 
all 3 types occurred and this reached the maximum level by the time the acute inflammatory stage of the illness had subsided.

Patient 4. This 28-year-old man developed a severe primary toxic reaction to the virus inoculum which began 5 hours post-injection and resembled that described for patient 2. An episode of mild acute respiratory illness which followed on day 4 was characterized by a granular conjunctivitis, rhinitis, and pharyngitis with lymphatic hyperplasia in the pharynx. Constitutional symptoms were absent. The patient did not feel feverish and his temperature was not taken. The injection site was moderately inflamed. Mild cervical and axillary (injection side) lymphadenopathy were present on day 5 and lasted about 3 weeks. There was no further significant change during the remainder of the 182-day observation period. The chest $\mathrm{X}$-rays were negative throughout and there was no significant alteration in either the total and differential white blood cell counts or in the serum bilirubin level. Throat cultures taken on days 4 and 6 revealed a normal flora and attempts to recover adenovirus from the conjunctivae on day 6 and from the throat on days $4,5,6$, and 10 were not successful. The patient had neutralizing antibody against types 3 and 7 prior to injection but not against type 4 . There was a marked increase in neutralizing antibody against all 3 types during convalescence.

Patient 5. This 36-year-old man who was in good health by history and physical examination, showed a sedimentation rate (Wintrobe method) of $27 \mathrm{~mm}$. per hour and a peripheral blood eosinophilia of 40 per cent. The volunteer was given adenovirus in spite of these abnormalities and these did not appear to influence the progress of the illness induced by viral inoculation. The patient developed a mild acute respiratory illness with constitutional symptoms on the third day post-inoculation. This lasted for 5 days and was characterized by fever to $99.8^{\circ} \mathrm{F}$., a complaint of chilliness and malaise, rhinitis, mild pharyngitis with tonsillar hypertrophy, cervical and axillary (injection side) lymphadenitis and inflammation of the injection site. The routine physical examinations during the remaining of the 171-day observation revealed no further abnormalities. X-rays of the chest were negative throughout. The serum bilirubin levels were not elevated and the eosinophilia, originally present, persisted throughout the period of observation. Throat cultures made on the fourth and sixth days postinoculation revealed a normal flora and virus recovery attempts from the eye on day 6 and the throat on days 4,5 , and 6 were negative. Neutralizing antibody against type 3 virus only was present in the initial serum specimen and there was an increase to types 3 and 7 virus but not type 4.

Patient 6, Figure 3. This 36-year-old man was found to be in excellent health by history and by physical and laboratory examinations. He had received three 1-ml. injections of the killed monkey kidney adenovirus vaccine 3 months previously. On the first day following administration of the live adenovirus he developed a mild sore

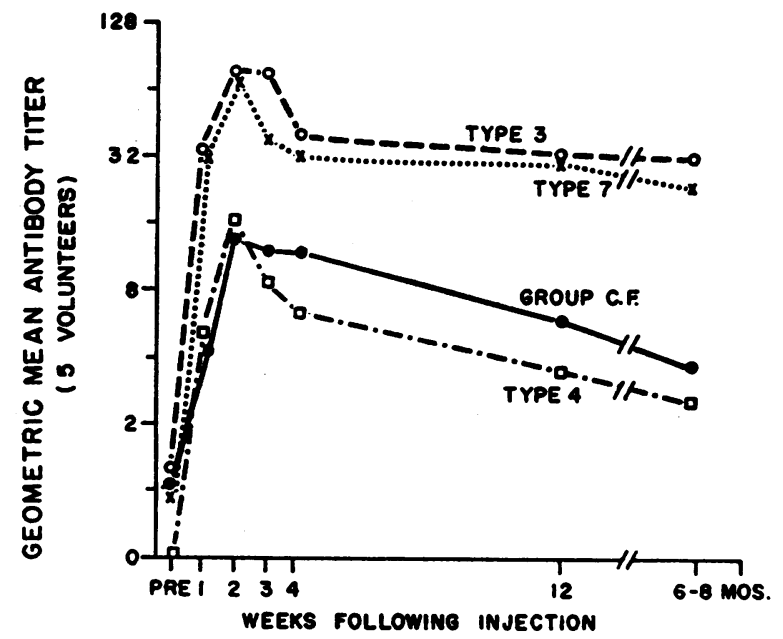

Fig. 4. Neutralizing and C.F. Antriody Patterns in Human Volunteers Given Trivalent Pool of Live ADENOVIRUS

throat which he attributed to a "cold." Slight erythema of the posterior pharynx was noted on examination and this persisted for 7 days without accompanying fever or malaise. On the fourth day post-inoculation, the patient developed a mild rhinitis with erythema, congestion of the nasal mucosa, and a clear mucoid discharge. There was a moderate amount of inflammation at the injection site, and slight cervical and moderate axillary (injection side) lymphadenitis. This non-febrile illness was so mild that. it would likely have gone unnoticed had it not been anticipated and its relationship to the injection of live virus. could not be assessed. There were no physical abnormalities of significance during the remainder of the 166day period of observation.

Chest X-rays made prior to and on the seventh day post-inoculation were negative. The total and differential white blood counts remained normal and the serum bilirubin levels were not elevated. Throat cultures on days 4 and 6 revealed no abnormal flora. Virus recovery attempts from throat washings collected on days $4,5,6$, and 13 yielded no virus. Neutralizing antibody to all three types was present in the pre-inoculation specimen and there was no alteration in these titers.

\section{Serological response in volunteers}

The mean serological response in the five volunteers (patients 1 to 5) who had not received adenovirus vaccine prior to injection of live virus is presented in Figure 4. Among the five individuals, only two had detectable neutralizing antibody against type 3 virus in the pre-inoculation specimen, three had antibody against type 7 , and none had antibody against type 4 . The mean titer against types 3 and 7 , which was about $1: 1$ in the pre- 
injection specimen, increased to $1: 34$ seven days later and reached a maximum of $1: 74$ by the fourteenth day. The titers were diminished only slightly during the 6 to 8 months which followed. The type 4 antibody rose from zero level to a maximum of $1: 17$ by day fourteen and the titer was reduced to $1: 3$ by the end of 6 to 8 months. The C.F. antibody, which is directed against a "soluble" antigenic component $(18,19)$ and appears not to be concerned directly with immunity to infection with these agents, rose from a mean level of $1: 1$ to the maximum $1: 16$ and diminished to $1: 4$ by the end of 6 to 8 months.

\section{DISCUSSION}

Previous workers have reported the development of acute respiratory illness in human volunteers inoculated nasally with the filtered throat washings from a patient with $\operatorname{ARD}(4,20,21)$ and in human beings inoculated by the conjunctival or nasal route with adenoviruses propagated in tissue culture $(22,23)$. The present experiments represent the first successful reproduction of acute respiratory disease in persons given adenovirus by a parenteral route and strongly support the etiological significance of these agents in respiratory illnesses of man. Earlier experiments (3, 6, $7)$, in which adenoviruses were given parenterally by the intramuscular, intracutaneous, and intratumor routes, and more recently (24), intravenously, presented evidence of viral infection but without significant illness. The reason for the present experience, in contrast to the earlier, has not been determined but differences in the viral inocula employed may be of significance. The adenoviruses employed heretofore were grown in tissue cultures of human epidermoid carcinoma or monkey kidney, while the present virus was propagated in human intestine cell cultures. Further, the infectivity titer of the present inoculum was 10 times as great as that employed before (7) and three types of virus were injected simultaneously instead of a single type.

The clinical course which followed injection of the trivalent virus pool was in three phases. The initial phase, which lasted 2 or 3 days, was the incubation period. During this period, three of the volunteers experienced a febrile toxic reaction with constitutional symptoms. This is believed to have been due to toxicity of the viral inoculum and to be unassociated with infection. The second phase, which began 3 or 4 days post-inoculation and lasted for 4 or 5 days, represented the stage of acute respiratory illness. The third phase was the period of convalescence. The acute respiratory illness induced by adenovirus resembled closely that described by Dascomb and Hilleman (16) for laboratory-proved cases of the natural disease, and also the previous clinical descriptions of febrile catarrh (25) and of $\operatorname{ARD}(14,15)$ with conjunctival inflammation such as occurs in pharyngo-conjunctival fever (7). Thus, there were fever, constitutional symptoms, and inflammation of the mucosae of the eyes, ears, nose and throat accompanied by characteristic lymphoid hyperplasia in the pharynx and conjunctivae. Exudate, such as commonly occurs in natural adenovirus disease (16), was also present on the hyperplastic lymphatic tissue in the throat of case 1 . Cervical lymphadenopathy was a common feature of both the natural and experimental disease. None of the volunteers, however, presented signs or symptoms indicative of spread of the inflammatory process to the larynx, trachea or the lower respiratory tract such as occurs in naturally-acquired adenovirus infections. The 2 or 3-day incubation period of the disease was consistent with the 2 to 7-day period reported by other workers who employed different kinds of adenovirus preparations given by different routes (20-23).

The failure to recover adenovirus from the eyes and throats of the volunteers was not referable to the isolation techniques employed since adenoviruses were concurrently recovered, in the same laboratory, from 44 of 55 serologically proved cases of naturally occurring adenovirus disease (12). Instead, the negative recovery attempts clearly excluded the presence of detectable virus in the conjunctival and nasopharyngeal secretions of the volunteers during their illness. This absence of virus from the secretions might be related to the intramuscular route of infection in contrast to the natural route which is presumed to be via the respiratory tract and possibly the conjunctivae. Of greater probable significance was the rapid increase in amount of neutralizing antibody in the volunteers against all three virus types which had achieved the maximal or near maximal level by the fourth or fifth day after onset of illness. 
Such a circumstance seems incompatible with the excretion of significant amounts of viable virus and might account also for the relatively mild form of the illness in the volunteers. This rapid antibody increase is in striking contrast to the natural infection in which the homologous neutralizing antibody is absent or of very low level during the acute illness and does not usially attain the maximum titer until 3 weeks after onset of the disease. Indeed, this pattern resembles the rapid antibody response which follows use of killed monkey kidney adenovirus vaccine $(10,11)$, in which there is marked increase after 1 week reaching maximum level by 2 weeks post-inoculation, and strongly suggests that the trivalent material given the volunteers acted as a live virus challenge dose combined with a sufficient amount of viable or non-viable virus to permit immediate stimulation of the antibody mechanism.

Live adenovirus vaccine presents the same potential and theoretical advantages as may be expected for living vaccines against other diseases such as poliomyelitis, influenza, rabies, yellow fever, typhus and others. Thus, the immunity induced by live virus might be broader immunologically and less type or strain specific, may be longer lasting, and a much smaller quantity of virus may be needed to achieve the desired effect. The last mentioned factor may be of great importance for the adenovirus vaccine since, according to present estimates, the killed monkey-kidney vaccine may prove expensive to produce and assay. Likewise, employment of living vaccine may be of advantage in young children in whom prior experience with these agents may be lacking and the recall phenomenon consequently non-operative.

The $1 \mathrm{ml}$. of undiluted viral inoculum given the volunteers, which represents a large dose of adenovirus, was employed for the purpose of providing an adequate test dose for detection of possible infectious hepatitis A or B virus. It is believed that appropriate reduction in amount of virus given might, as found in previous experiments $(3,6,7)$, have stimulated antibody formation without causing significant clinical illness. The high degree of effectiveness of the killed monkey kidney vaccine $(10-12)$ and the theoretical objections to the use in man of virus grown in serially propagated cells of human origin have led us to delay further tests of the human intestine preparation in man.

\section{SUMMARY}

1. Human volunteers injected intramuscularly with a pool of types 3,4 , and 7 adenovirus propagated in tissue cultures of human embryo intestine developed acute respiratory illness which began 2 or 3 days post-inoculation and lasted for 4 or 5 days. The illness was characterized by fever and inflammation of the mucous membranes of the eyes, ears, nose and throat with hyperplasia of the submucosal lymphatic tissue of the conjunctivae and pharynx and hypertrophy of the cervical lymph nodes. The disease resembled the naturally occurring illness "ARD" or "febrile catarrh" with conjunctivitis as described for "pharyngoconjunctival fever." Three volunteers experienced a febrile toxic reaction which followed several hours after inoculation of virus.

2. All volunteers, except one who had previously received killed virus vaccine, showed a marked increase in neutralizing antibody against all three types of virus and in complement fixing antibody. The antibody titers were diminished, on the average, 3 to 6 -fold by the end of the 6 to 8 month observation period.

3. The significance of the findings in relation to the reproduction of the disease following parenteral inoculation of virus and the use of live virus vaccine against adenovirus infections are discussed.

\section{REFERENCES}

1. Hilleman, M. R., and Werner, J. H., Recovery of new agent from patients with acute respiratory illness. Proc. Soc. Exper. Biol. \& Med., 1954, 85, 183.

2. Hilleman, M. R., Werner, J. H., and Stewart, M. T., Grouping and occurrence of RI (prototype RI-67) viruses. Proc. Soc. Exper. Biol. \& Med., 1955, 90, 555.

3. Huebner, R. J., Rowe, W. P., Ward, T. G., Parrott, R. H., and Bell, J. A., Adrenoidal-pharyngeal-conjunctival agents. A newly recognized group of common viruses of the respiratory system. New England J. Med., 1954, 251, 1077.

4. Ginsberg, H. S., Badger, G. F., Dingle, J. H., Jordan, W. S., Jr., and Katz, S., Etiologic relationship of the RI-67 agent to "acute respiratory disease (ARD)." J. Clin. Invest., 1955, 34, 820.

5. Enders, J. F., Bell, J. A., Dingle, J. H., Francis, T., Jr., Hilleman, M. R., Huebner, R. J., and Payne, A. M.-M., "Adenoviruses": group name proposed for new respiratory-tract viruses. Science, 1956, 124, 119.

6. Hilleman, M. R., Werner, J. H., Dascomb, H. E., and Butler, R. L., Epidemiologic investigations with 
respiratory disease virus RI-67. Am. J. Pub. Health, 1955, 45, 203.

7. Southam, C. M., Hilleman, M. R., and Werner, J. H., Pathogenicity and oncolytic capacity of RI virus strain RI-67 in man. J. Lab. \& Clin. Med., 1956, 47, 573.

8. Rustigian, R., Johnston, $P$., and Reinhart, $H$., Infection of monkey kidney tissue cultures with virus-like agents. Proc. Soc. Exper. Biol. \& Med., 1955, 88, 8.

9. Hull, R. N., Minner, J. R., and Smith, J. W., New viral agents recovered from tissue cultures of monkey kidney cells. I. Origin and properties of cytopathogenic agents S.V.1, S.V .2, S.V., S.V.8, S.V.e, S.V..11, S.V.12, and S.V.15. Am. J. Hyg., 1956, 63, 204.

10. Hilleman, M. R., Stallones, R. A., Gauld, R. L., Warfield, M. S., and Anderson, S. A., Prevention of acute respiratory illness in recruits by adenovirus (RI-APC-ARD) vaccine. Proc. Soc. Exper. Biol. \& Med., 1956, 92, 377.

11. Hilleman, M. R., Warfield, M. S., Anderson, S. A., and Werner, J. H., Adenovirus (RI-APC-ARD) vaccine for prevention of acute respiratory illness. 1. Vaccine development. J. A. M. A., 1957, 163, 4.

12. Stallones, R. A., Hilleman, M. R., Gauld, R. L., Warfield, M. S., and Anderson, S. A., Adenovirus (RI-APC-ARD) vaccine for prevention of acute respiratory illness. 2. Field evaluation. J. A. M. A., 1957, 163, 9.

13. Henle, G., and Deinhardt, F., The establishment of strains of human cells in tissue culture. J. Immunol., In press.

14. Commission on Acute Respiratory Diseases, Acute respiratory disease among new recruits. Am. J. Pub. Health, 1946, 36, 439.

15. The Commission on Acute Respiratory Diseases, Clinical patterns of undifferentiated and other acute respiratory disease in army recruits. Medicine, 1947, 26, 441.

16. Dascomb, H. E., and Hilleman, M. R., Clinical and laboratory studies in patients with respiratory dis- ease caused by adenoviruses (RI-APC-ARD agents). Am. J. Med., 1956, 21, 161.

17. Bell, J. A., Rowe, W. P., Engler, J. I., Parrott, R. H., and Huebner, R. J., Pharyngoconjunctival fever. Epidemiological studies of a recently recognized disease entity. J. A. M. A., 1955, 157, 1083.

18. Hilleman, M. R., Tousimis, A. J., and Werner, J. H., Biophysical characterization of the RI (RI-67) viruses. Proc. Soc. Exper. Biol. \& Med., 1955, 89, 587.

19. Hilleman, M. R., Werner, J. H., Dascomb, H. E., Butler, R. L., and Stewart, M. T., Epidemiology of RI (RI-67) group respiratory virus infections in recruit populations. Am. J. Hyg., 1955, 62, 29.

20. Commission on Acute Respiratory Diseases, Experimental transmission of minor respiratory illness to human volunteers by filter-passing agents. I. Demonstration of two types of illness characterized by long and short incubation periods and different clinical features. J. Clin. Invest., 1947, 26, 957.

21. Commission on Acute Respiratory Diseases, Experimental transmission of minor respiratory illness to human volunteers by filter-passing agents. II. Immunity on reinoculation with agents from two types of minor respiratory illness and from primary atypical pneumonia. J. Clin. Invest., 1947, 26, 974.

22. Ward, T. G., Huebner, R. J., Rowe, W. P., Ryan, R. W., and Bell, J. A., Production of pharyngoconjunctival fever in human volunteers inoculated with APC viruses. Science, 1955, 122, 1086.

23. Roden, A. T., Pereira, H. G., and Chaproniere, D. M., Infection of volunteers by a virus (A.P.C. type 1) isolated from human adenoid tissue. Lancet, 1956, 2, 592.

24. Smith, R. R., Huebner, R. J., Rowe, W. P., Schatten, W. E., and Thomas, L. R., Studies on the use of viruses in the treatment of carcinoma of the cervix. Cancer, 1956, 9, 1211.

25. Stuart-Harris, C. H., Andrewes, C. H., and Smith, W., A study of epidemic influenza. With special reference to the 1936-1937 epidemic. Med. Res. Council, Gt. Britain, Spec. Rept. Series, No. 228, London, H.M. Stationery Office, 1938. 